Meta

Journal des traducteurs

Translators' Journal

\title{
Swahili Terminological Modernization in Tanzania. What Are the Register Users' Views?
}

\section{H. J. M. Mwansoko}

Volume 36, numéro 1, mars 1991

La terminologie dans le monde : orientations et recherches

URI : https://id.erudit.org/iderudit/003684ar

Aller au sommaire du numéro

Éditeur(s)

Les Presses de l'Université de Montréal

ISSN

0026-0452 (imprimé)

Découvrir la revue

Citer cet article

Mwansoko, H. J. M. (1991). Swahili Terminological Modernization in Tanzania. What Are the Register Users' Views? Meta, 36(1), 301-310.
Résumé de l'article

Cet article rend compte des observations faites à partir d'une recherche effectuée auprès des utilisateurs du swahili sur les principes et procédés régissant le travail terminologique swahili dans l'espoir que le National Swahili Council tienne compte des nouvelles observations empiriques pour la planification de la terminologie moderne swahili. 


\title{
SWAHILI TERMINOLOGICAL MODERNIZATION IN TANZANIA. WHAT ARE THE REGISTER USERS' VIEWS?
}

\author{
H. J.M. MWANSOKO \\ University of Dar es Salaam, Dar es Salaam, Tanzania
}

\begin{abstract}
RÉSUMÉ
Cet article rend compte des observations faites à partir d'une recherche effectuée auprès des utilisateurs du swahili sur les principes et procédés régissant le travail terminologique swahili dans l'espoir que le National Swahili Council tienne compte des nouvelles observations empiriques pour la planification de la terminologie moderne swahili.
\end{abstract}

\section{INTRODUCTION}

Despite the call made by Fishmen et al. (1971: 301) to language planners to investigate, for implementational purposes, "the attitudes or preferential views of the target populations with respect to the language-planning products", few studies have appeared in terminological modernization (henceforth TM) planning literature on the register users'attitudes towards their respective language planning agencies' (henceforth L.PA) terminology work. Jernudd (1977), for example, has reported on the students', teachers' and textbook writers' views on agency terminology work in Indonesia and Israel. His findings suggest that in many instances the register users' views conflicted with those of the LPA officials. In Swahili scholarship the question of the register users' views on Swahili terminology work has not only been given prominence in scholarly discussions, but also the reported users' attitudes towards the Swahili terminology work (see eg. Khamisi 1981, Mdee 1980) seem not to have made any impact on the official Swahili TM planning agency, namely the National Swahili Council (henceforth NSC). For example, although Khamisi (1981: 5) reported that most of the Swahili register users, and especially those from higher educational circles (eg. the university and the professional levels) favoured English as a source of borrowing Swahili loan terms, the NSC to date continues to formally give Arabic prominence as a source of Swahili loans (see Kakulu, 3, 1982, Mbughuni 1983: 9).

The purpose of the present study is to report further and more recent observations concerning the register users' views on the general principles and procedures of Swahili terminology work in the hope that as more empirical observations on this issue come to light, the NSC would ultimately realize the need to take them into serious consideration as a prerequiste for successful Swahili TM planning.

The study might also challenge other LRAs, particularly in developing nations, to critically examine their target populations' attitudes towards agency language products as a variable for successful implementation of language (corpus) planning. As Jernudd (1973: 16) has rightly observed:

"Successful implementation (of any aspect of the language planning) implies an understanding of people's attitudes to language, beliefs about language, and language proficiency - briefly, the context of propagation of products of language planning". 
The study is based on a field research I conducted in August

- October 1988. During the field work 460 closed questionnaires were circulated to 15 schools/colleges ${ }^{1}$ and the University of Dar es Salaam and completed by 25 students and two teachers in each school/college, 40 1st year University students majoring in Swahili and 15 university Swahili lecturers/researchers. The secondary students were in form III while the college teacher trainees were in their second year of study. My target populations were Swahili teachers and students because only Swahili linguistics and literature are officially taught in Swahili up to university level. The questions asked of these informants sought the following information:

- the methods of TM which the register users preferred for Swahili,

- he source languages which the register users preferred to be used for developing

Swahili terminologies,

- the criteria of efficient terminology which the informants regarded most crucial in developing Swahili terms,

- the principles which the target populations regarded as most pertinent for the selecting the roots for Swahili terminology,

- the spelling convention the terminology users preferred for English-based Swahili loans,

- the word order the informants preferred for the Swahili complex terms borrowed from English,

- the procedure of TM which the register users preferred to be followed in developing the Swahili technical terms.

An analysis of the informants' responses to the above questions is discussed below.

\section{REGISTER USERS' VIEWS ON SWAHILI TM}

We propose to discuss these views on the basis of seven variables which correspond to the questions asked of the informants, viz:

1. preference of TM methods for Swahili,

2 preference of source languages for Swahili TM,

3. criteria of efficient terminology,

4. principles for selecting term roots,

5. spelling of English-based loan terms,

6. word order of English-based complex terms,

7. procedure of Swahili TM.

\section{PREFERENCE OF TM METHODS FOR SWAHILI}

The informants were asked which of the following methods of terminology elaboration they thought should be preferred for Swahili:

1. adopting an already available and currently used swahili word of same meaning to the foreign concept/term,

2. compounding of existing words,

3. adding affixes to available steems to make new terms (i.e. derivation),

4. giving an already existing word additional specialized technical meaning (i.e. semantic expansion),

5. inventing a new stem (i.e. word manufacture).

They were required to rate their priority of the methods in a five-point scale (i.e. first, second... fifth choice).

The results of their responses indicate that the use of Swahili equivalents to the foreign concepts and terms was selected first choice Swahili TM method by an average of $46,9 \%$ of the respondents, whereas $11,3 \%, 25,3 \%, 7,5 \%$ and $7,7 \%$ of the informants 
chose this method as their second, third, fourth and fifth preference, respectively. Compounding was named first choice by on average $23,1 \%$ of the respondents, as second choice by $22,3 \%$ of the informants, as third choice by $30,5 \%$ of the informants, as fourth choice by $15,7 \%$ of the respondents and as fifth choice by $8,5 \%$ of the informants. Derivation, on the other hand, was selected first, second, third, fourth and fifth choice Swahili TM method by $10,6 \%, 44 \%, 15,7 \%, 24,7 \%$ and $5,1 \%$ of the respondents, respectively. On average only $5 \%$ of the informants named semantic expansion as their first choice Swahili TM method. $14,3 \%$ of them named this method as their second choice, $17,4 \%$ as third choice, $42,3 \%$ as fourth choice and $21,1 \%$ as their fifth choice. Lastly, word manufacture was selected method number one for developing Swahili terminology by only an average of $12,9 \%$ of the informants, while $8,1 \%, 9,9 \%, 10,1 \%$ and $56,5 \%$ of the respondents rated this method as their second, third, fourth and fifth choice, respectively.

On the basis of the above findings it can be concluded that the adoption of already available and currently used Swahili words of similar meanings to the foreign concepts and terms is the most preferred method of expanding Swahili terminological vocabulary. The second most preferred method is derivation, followed by compounding and semantic expansion. Word manufacture appears to be the least preferred internal means of Swahili word formation.

Thus in the course of modernizing Swahili it would be advisable for those charged with the task of elaborating the Swahili technical terms to take into consideration the register users' preferences of the TM methods for Swahili. Such a consideration might positively contribute to the users" acceptance of the "official" terms.

As far as I am aware the NSC gives equal opportunity to all methods of Swahili terminology elaboration irrespective of their productivity in the language. It seems to be assumed by the NSC, at least implicitely, that there are no terminology expansion methods which can be judged as being more suitable than others for Swahili. This point of view, it should be argued, is erroneous, for according to terminology theory (see eg. Fodor 1983/4: 445-447) the productivity of the universally available TM methods depends on the phonological and grammatical structure of each individual language. On the basis of our research findings it is tempting to suggest that for Swahili the most productive and, hence, most preferred means of terminology expansion are the use of Swahili equivalents to foreign concepts and terms, derivation, compounding and, to some extent, semantic expansion. In the course of developing Swahili technical terms these methods of lexical expansion should therefore be given priority by the NSC - sponsored terminology commitees (henceforth TC).

\section{PREFERENCE OF SOURCE LANGUAGE FOR SWAHILI TM}

Five source languages deemed productive in Swahili terminology work were identified and the informants were asked which ones among the identified languages they preferred as sources of Swahili terminology. They were to rank their choices in a fivepoint scale.

The analysis of their responses indicate that the overwhelming majority of the informants (on average 78,9\%) selected Greco-Latin as their fifth choice source language for borrowing Swahili terms. Only a tiny proportion of the respondents, i.e. on average $0,3 \%, 2,7 \%, 4,2 \%$ and $14,1 \%$ named this source as first, second, third and fourth choice, respectively. Arabic was ranked first language source from which Swahili terms could be borrowed by an average of only $0,7 \%$ of the respondents. $1,6 \%$ of the respondents ranked it second choice, $24,3 \%$ ranked it third choice, $13,4 \%$ ranked it fifth choice, while the majority of the informants, i.e. 57,6\% ranked Arabic as their fourth most preferred source 
of Swahili loans. English was considered at the most convenient source language for Swahili loans by an average of only $2,4 \%$ of the informants. $5,1 \%, 23,6 \%$ and $3,7 \%$ of the respondents selected English as the second, fourth and fifth most preferred source for borrowing Swahili loan terms. The majority of the informants, i.e. on average $62,8 \%$, ranked English as their third most preferred source of Swahili terms. Swahili and its varieties with an average preference score of $94,8 \%$ is undoubtedly regarded as the most convenient source of Swahili terms. Indigenous languages related to Swahili, for example the Bantu languages, were ranked second most preferred sources of Swahili terms by the overwhelming majority of the informants - i.e. on average $87,9 \% .1,9 \%$ of the respondents ranked this source language as first choice, whereas $5 \%$, another $1,9 \%$ and $2,6 \%$ of the informants ranked it as third, fourth and fifth choice, respectively.

The above findings show that the most preferred source language for developing Swahili technical terms is Swahili itself together with its non-standard varieties. The second most preferred source languages are the other indigenous languages of Tanzania, particularly the Swahili related Bantu languages. The third preference is English, the fourth Arabic and the last - Greek and Latin.

This order of priority of the terminology sources is the most probably influenced by nationalistic sentiments, for the emphasis on greater use of Swahili, its non-standard varieties and other local Bantu languages prior to borrowing from foreign languages is, at least at the present, groundless because very little lexicographic research into the nonstandard varieties and the other Tanzanian Bantu and non-Bantu languages had been done so far to enable them to become a significant resource of technical terminologies (Dunn 1985: 38-39, Khamis 1986: 5, Macwilliam 1988). Therefore in the actual terminology elaboration work it is very unlikely that the non-standard Swahili varieties and the Tanzanian local languages would be productive.

It should also be noted that although English is usually relegated to the last position among the external terminology sources for Swahili by the NSC, this being the case especially in the humanities, our informants, who are the actual users of Swahili terminology, gave it prominence as a source of borrowing among the foreign languages. This observation ought to be noted by the NSC officials, for it implies that Swahili loans based on English might have a higher chance of being accepted by the register users than those based on, say, Arabic or Greco-Latin. I should add that the register users' preference of English as a source of foreign terms should be considered by the NSC as a positive factor for enhancing terminology standardization in Swahili, for it means that if the NSC decides to base all or most of the Swahili international terms on English, it will be easy for the Council to formulate detailed guidelines of incorporating such loans in Swahili - a factor which will make terminology standardization much easier and more orderly than is now. The present guidelines of Swahili terminology development seem to be meant to carter for all source languages. And this is one reason why such guidelines are very general and even misleading. In Bahasa Malaysia and Bahasa Indonesia terminology standardization could not be effectively undertaken until one language (viz. English) was selected as the only source of loanwords for these languages (Hussain 1986: 238). It would seem likely that the NSC and Swahiliists in general will see the same advantages of basing loan terms on a single language as has been experienced in Bahasa Malaysia and Bahasa Indonesia.

\section{CRITERIA OF EFFICIENT TERMINOLOGY}

The informantd were asked, if they were to formulate a policy for the development of terminology in Swahili, which of the following features would they emphasize for the terms introduced into the language: 
1. the correspondence of the phonological and grammatical structure of the term with that of Swahili,

2. the precision of the term,

3. the derivational productivity of the term,

4. the concisiness of the term,

5. the consistency of the term.

Their responses show that on average $31,4 \%, 42,3 \%, 10,3 \%, 7,4 \%$ and $8,7 \%$ of the informants regarded the phonological and grammatical correspondence of the new terms with that of Swahili the first, second, third, fourth and fifth, respectively, most important feature of the new terms. The precision criterion was ranked first requirement for new terms by an average of $46,3 \%$ of the respondents. It was ranked second, third, fourth and fifth most important feature of terminology by $23,3 \%, 11,3 \%, 13 \%$ and $9,5 \%$ of the informants, respectively. The derivational productivity of the terms was selected first, second, third, fourth and fifth most important feature of the new terms by an average of $13,3 \%, 13,1 \%, 28,3 \%, 35,3 \%$ and $10,1 \%$ of the respondents, respectively, whereas $2,4 \%$, $9,4 \%, 17,6 \%, 16,1 \%$ and $54,5 \%$ of the register users who completed the questionnaire ranked consisiness of the term as first, second, third, fourth anf fifth most crucial feature of the new Swahili terms. The consistency of the terms, on the other hand, was regarded as the most crucial feature of the newly-coinced terms by only an average of $11,8 \%$ of the informants. $10,9 \%, 28,2 \%$ and $17,1 \%$ of the respondents considered this criterion as the second, fourth and fifth, respectively, most important feature required for developing Swahili terminology. The majority of the informants, i.e. $31,2 \%$ regarded consistency of the terms as the third most important requirement of efficient new terms.

The foregoing discussion leads to the conclusion that the informants' priority order of the crucial features required for developing efficient Swahili terms is as follows:

1. that the terms formed should be precise,

2. that the new terms' phonological and grammatical structure should conform to that of Swahili which is the target language,

3. that the terms should be consistent,

4. that that terms should be productive of derivations,

5. that the terms should be concise.

Unfortunately, earlier evaluation studies of existing Swahili terms (see eg. Kiingi 1981, Mdee 1983, MacWilliam 1985) have shown that most of the already developed Swahili terms do not have the above mentioned criteria of efficient terminology. Kiingi (1981), for example, demonstrated that quite a number existing Swahili terms were not productive of derivations. Mdee (1983) and MacWilliam (1985), on the other hand, found that in most cases Swahili terms borrowed from English did not follow a regular and recurrent pattern, that is, they were incorporated in Swahili inconsistently.

Therefore in order to develop efficient and, hence, acceptable by the register users Swahili terms, it is important that the NSC takes enough precaution to ensure that all Swahili terms elaborated under its auspices reflect the above-mentioned criteria of efficient terminology, particularly the precision and grammatical harmony criteria.

\section{PRINCIPLES FOR SELECTING TERM ROOTS}

The question read: Which of the principles below do you find most pertinent for selecting roots for Swahili terminology?

1. that the terms are recognizably international, i.e. at least similar to international terms,

2. that the terms derive from Swahili sources and patterns,

3. that the terms derive from international as well as Swahili sources. 
Only $6,9 \%$ of the informants preferred to base all Swahili technical terms on international terms. The number of teachers/tutors and university students preferring to derive the terms from Swahili sources and patterns, on the one hand, and those preferring to derive the terms from international as well as Swahili sources, on the other hand, were almost the same (i.e. $43,3 \%$ and $47,5 \%$, respectively). The overwhelming majority of the university lecturers/researchers (i.e. $84,8 \%$ ) preferred to base the new Swahili terms on both Swahili and international roots. In general, however, most of the respondents, i.e. on average $61,4 \%$, were of the opinion that both Swahili and international terms should contribute towards the terminological enrichment of Swahili.

This view, it should be noted, conflicts with official terminology agency point of view emphasizes on the indigeneity of terminology and considers international (eg. English) terminological sources as only a last resort.

\section{SPELLING OF ENGLISH-BASED LOAN TERMS}

Inspite of the official resistance to Anglicisms the number of English-based loans in Swahili has been rising steadly all the time most probably because of the register users' preference to English among the foreign terminology source languages. In order to provide ourselves with the basis for suggesting ways of ensuring that such loans are consistently incorporated into Swahili, we asked the informants which of the following spelling conventions of English-based Swahili loans did they prefer and why?

1. spelling based on the English pronunciation of the terms (eg. fyusi fuse),

2. spelling based on the English orthography of the terms (eg. fueli fuel),

3. spelling based on both the English pronunciation and orthography of the terms (eg. nitrojeni nitrogen).

The overwhelming majority of the informants (on average $77,7 \%$ ) preferred to spell the Swahili terms borrowed from English on the basis of their English pronunciation as perceived by the Swahili speakers. The reason provided for this choice by almost all respondents is that this is the way such loans are traditionally being assimilated in Swahili. On average 17,6\% of the responents preferred basing these loans on English orthography arguing that such a spelling convention would very much ease the transliteration of foreign terms into Swahili. The third type of spelling, i.e. the one based on a mixture of both English pronunciation and orthography, was very rarely selected by the informants. Only an average $4,8 \%$ of them selected it.

The NSC's policy on the spelling of the Swahili English-based loan terms seems to be rather "liberal". As far as I am aware all the above discussed spelling conventions appear to be given equal weight in the language. This is a very inconsistent way of spelling loan terms and it contradicts one of the major requirements of terminology, viz. consistency of terms. It is therefore recommended that, for the sake of ensuring acceptability of the loan terms by most register users, the NSC should decree (and strive to adhere to the decree) that henceforth all Swahili terms borrowed from English would be spelt only on the basis of their English pronunciation as perceived by the Swahili speakers. However, if the NSC's priority is to ensure that the loan terms are consistently assimilated in the target language, then in my opinion only the spelling convention based on English orthography can render such a facility. Unlike the pronunciation oriented spelling which necessitates waiting until one hears how a certain term is pronounced by a native English speaker or sees how it is transcribed in, for example, a technical dictionary before one can correctly spell, all the orthography-oriented spelling involves is seeing a new term from an external source such as English and transliterating it into Swahili following its surface (i.e. written) form. 


\section{WORD ORDER OF ENGLISH-BASED COMPLEX TERMS}

We asked the register users who completed the questionnaire: If you borrowed from English a complex term of the type Noun-Noun or Adjective-Noun in which word order would you prefer to write it in Swahili?

1. following English-based word order (eg. askobiki asidi ascorbic acid),

2. following the normal Swahili word order (eg. asidi askobiki ascorbic acid).

The informants' responses indicate that the majority of the informants (on average $68,2 \%$ ) prefer to write English-based complex terms following the usual Swahili word order (i.e. head word + modifier). Such rendering of the complex terms, the informants argue, conforms to target language's morphosyntax.

Until recently the official policy regarding the word order of such loaned complex terms was to render them following both English-based word order and the normal Swahili word order, cf.

kalisiamu kloraidi maginiziamu oksaidi

\section{calcium chloride}

magnesium oxide

versus

asidi haidrokloriki

asidi amino

\section{hydrochloric acid}

amino acid

(see the NSC's Tafsiri Sanifu [Standard Translations] Vol. 4, 1980).

However, of late the official directive is to write these terms following the normal Swahili word order. And an attempt to render them in the correct word order has been made by the panelists (who included NSC officials too) of the Regional Workshop on the Preparation, Standardization and Dissemination of Technical Terms in Physics, Chemistry, Biology and Linguistics organized by the Institute of Kiswahili Research (henceforth IKR) in 1987 (see the Workshop's Report).

Nevertheless, despite the register users' support to Swahili's normal word order it is important to note that quite a large proportion of the school and college teachers/tutors (i.e. 53,3\%) preferred to use the English-oriented word order arguing that such word order preserved the "international flavour" characteristic of the most technical terms in the so-called exact sciences. Although the international recognizability of Swahili complex terms based on English word order cannot be disputed, the fact remains that such word order contradicts Swahili's morphosyntax does not correctly reflect the meanings of the concepts being represented by the various complex terms. For example, kalisiamu kloraidi is not "calcium which contains chloride" but "chloride which has clacium in it" (cf. Besha 1986). But as is well known teachers and tutors are very influential users of the Swahili registers. And because of their influence it is very likely that the current mixing of the word order of complex terms (i.e. normal Swahili word order and English-based word order) will continue for quite some time.

\section{PROCEDURE OF SWAHILI TM}

After briefly explaining how the Swahili technical terms are elaborated and formally approved, we asked the informants if they supported the current procedure of Swahili TM which involves the separation of the processes of terminology elaboration and standardization or if they thought that both terminology elaboration and standardization should be undertaken by the one and the same terminology commitee, or if they had other suggestion(s).

Their responses indicated that the majority of the register users (i.e. on average $61,1 \%$ ) were of the opinion that both terminology elaboration and standardization should be undertaken by one and the same commitee (TC). The reasons advanced in support if 
this procedure included: first, such a procedure will quicken the process of terminology elaboration in Swahili; secondly, the procedure might reduce synonymy in Swahili terminology as the so-called standardization terms which are occasionally issued by the NSC to replace well established but not yet "standardized" terms will be eliminated.

This point of view conflicts with the views held by the NSC officials (see kakulu, $\mathrm{n}^{\circ} 3$, 1982) who advocate the separation of the processes of terminology elaboration and standardization -- a procedure supported by only an average of $37,1 \%$ of the informants. The reasons for supporting this procedure, according to the respective informants, are, first, that it is more "democratic" as it enables many experts (i.e. including those from the NSC) to participate in the process of code elaboration. Secondly, the procedure enables the work of the various TCs to be vetted by a higher authority, i.e. the NSC which "standardizes" and formally approves all new Swahili technical terms before they can be used in specialist communication. Such reasoning is not valid because the NSC does not have experts who may claim to be well versed with all aspects of human knowledge. As Selander (1980: 22-23) has righly observed:

"There are few if any people who are interested in or who have a command (of all aspects of human knowledge)... A civil engineer or an architect cannot be assumed to understand the terminology of an electrical engineer, or a chemist".

Consequently, it is hard to believe that the NSC is capable of standardizing the technical terms of all the subject fields comprising human knowledge. Besides, the NSC is essentially a language status planning body and not a corpus planning agency (cf. Dunn 1985). Terminology standardization involves conscious manipulation of the language code which is quite outside the NSC's brief.

As the International Organization for Standardization (ISO), the agency coordinating TM activities worldwide, suggests the process of terminology development which comprises the systematization of the concepts of the various subject fields, the definition of the concepts and the elaboration of their terms should be undertaken by specialist TCs, one for each subject or specialization. Such TCs, to be appointed by the LPAs responsible for TM planning, should comprise subject experts, a few terminologists who provide guidelines on actual terminology work, and a few linguists, who assist the TCs in the grammatical harmonization of the terms they create. Such procedure of terminology work is presently being followed by a growing number of national and international TM bodies (Sager 1984).

It is therefore highly recommended that this procedure (i.e. that of combining terminology elaboration and standardization) should also be followed in developing Swahili terminology. The procedure has theoretical backing and apart from hastening terminology work, the fact that the terms, following this procedure, are worked out by practicing subject specialists guarantees their quality and acceptability by the register users.

\section{CONCLUSION}

There are a number of observations emanating from this study which ought to be noted by Swahili language planners. First, although the NSC favours indigeneity of Swahili terminology, most register users would like Swahili itself as well as international terms to contribute to the terminological development of the language. It would therefore seem advisable for the NSC to revise its puristic tendencies in terminology work, otherwise the development of more sophisticated Swahili terms, especially in the exact sciences, might be impaired as most of them will, of necessity, originate from the international lexicon. Secondly, although the official policy is to relegate English to the 
last source language for Swahili loans, the majority of the informants give it prominence as a source of borrowing among the foreign languages. In the light of this we suggest that the time has come for the NSC to change its anti-English sentiments. English has practically proved to be a productive source of technical terms in Swahili and it should therefore be given not only legitimacy in terminology work, but also priority. Thirdly, the present procedure of Swahili TM whereby the NSC has instituted itself as the standardizer of technical terms of all aspects of human knowledge is not based on any particular terminology theory and serves only to prolong the process of code elaboration in Swahili. To hasten terminology work and to raise the quality and acceptability of the terms, it has been suggested that specialist TCs should coin and standardize the terms of their own subjects and specializations. We also note that the TCs which we have suggested ought to be formed for every subject should strive to improve the quality of the already developed Swahili terms for, as has been established in the study, most of them do not seem to be efficient.

\section{NOTE}

1. Among these educational institutions four secondary schools and one teachers' training college (TTC) were from Dar es Salaam, the capital city of Tanzania; four secondary schools and one TTC from Kilimanjaro Region which is 474 miles north of Dar es Salaam; and four secondary schools and one TTC from Mbeya Region, situated in the southern highlands of Tanzania.

\section{BIBLIOGRAPHY}

BESHA, R.M. (1986): "Uingizaji wa Maneno ya Kigeni katika Kiswahili", paper presented at the NSC's Workshop on Language Standardization Strategies, Dar es Salaam, 5-7 May, 1986.

DUNN, A.S. (1985): "Swahili Policy Implementation in Tanzania: The Role of the National Swahili Council (BAKITA)", Studies in the Linguistic Sciences, 15-1, Spring, pp. 31-47

FISHMAN, J.A., DAS GUPTA, J., JERNUDD, B.H. and J. RUBIN (1977): "Research Outline for Comparative Studies of Language Planning", J. Rubin and B.H. Jernudd (eds), Can Language Be Planned?, Honolulu, University Press of Hawaii, pp. 293-305.

FODOR, I. (1983/84): "Language Reforms of the Past and in the Developing Countries", I. Fodor and C. Hagège (eds), Language Reform: History and Future, II, Humburg, Buske, Verlag, pp. 441-454.

HUSSAIN, K.M. (1986): "The Problems of Standardization of Technical Terms in Indonesia and Malaysian Languages", G. Rondeau and J.C. Sager (eds), Termia 84, Gisrterm, pp. 236-240.

IKR (1987): Final Report of the Regional Workshop on the Preparation, Standardization and Disseminational of Technical Terms in Physics, Chemistry, Biology and Linguistics, Dar es Salaam.

JERNUDD, B.H. (1973): "Language Planning as a Type of Language Treatment", J. Rubin and R. Shuy (eds) Language Planning: Current Issues and Research, Washington, Georgetown University Press, pp. 11-23.

JERNUDD, B.H. (1977): "Linguistic Sources for Terminological Innovation: Policy and Opinion", J. Rubin et al. (eds), Language Planning Processes, The Hague, Mouton, pp. 215-236.

KAKULU, 3 (1982): "Kamati ya Kusanifu Lugha", BAKITA.

KHAMISI, A.M. (1981): "Kujenga Kiswahili kwa Kutumia Lugha za Kibantu", unpublished IKR seminar paper.

KHAMISI, A.M. (1988): "Current Trends in Language Standardization in Tanzania", paper presented at the International Symposium on Language Standardization in Africa, Mainz, W. Germany, 10-14 March, 1986.

KIINGI, K.B. (1981): "The lexical Expansion of Kiswahili as Conceived by the Institute of Kiswahili Research", unpublished paper.

MACWILLIAM, A. (1985): "Some Thoughts on Translation of Scientific Terminology in Kiswahili", Kiswahili, 52-1 \& 52-1, pp. 114-128.

MACWILLIAM, A. (1988): "Expanding Swahili Lexicon by Means of Bantu Languages", Meta, 33-4, pp. $577-579$.

MBUGHUNI, P.M. (1983): "Literary Terminology Coincing Exercise: Problems and Achievements", paper presented at the International Conference on Standardization of Kiswahili Terminologies, Dar es Salaam, 26 September - 10 October 1983. 
MDEE, J.S. (1980): The Degree of Acceptability of New Swahili Words: Speakers' Response and Analysis, unpublished M.A. dissertation, University of Dar es Salaam.

MDEE, J.S. (1983): "The Policy of Adapting Loanwords in Kiswahili as Conceived by BAKITA: a Critique", Multilingua, 2-2.

NSC (1980): Tafsiri Sanifu, 4.

SAGER, J.C. (1984): "Terminology and the Technical Dictionary", R.R.K. Hartmann (ed), LEXeter 83 Proceedings, Tübingen, Max Niemeyer Verlag, pp. 395-400.

SELANDER, E. (1980): "Language for Professional Use from the Swedish Point of View", International Journal of the Sociology of Language, 23, pp. 17-28. 